\title{
LEITURA - CONSTRUÇÃO DE SENTIDO
}

\section{Eliana Rosa Langer*}

RESUMO: Este trabalho pretende ser uma reflexão sobre leitura como um processo de interação entre escritor/texto/leitor, do qual resultará a construção do sentido do texto pelo leitor.

Palavras-chave: leitura, processo, interação, construção de sentido.

Como professora de língua estrangeira, ciente da importância do aprendizado de línguas estrangeiras, pois este abre as portas para outras culturas, possibilitando uma visão de mundo mais abrangente, tenho refletido bastante sobre as questões que envolvem o ensino/aprendizagem de uma língua estrangeira em geral e no caso específico do "hebraico", idioma com o qual trabalho.

Alguns idiomas estrangeiros, e o hebraico é um exemplo disto, oferecem aos estudantes brasileiros poucas oportunidades de contato com os mesmos, por serem línguas pertencentes a grupos culturais muito distantes da realidade vivida por nossa sociedade, nestes casos, a leitura seria o elo que manteria nosso aprendiz em contato com a língua alvo. Habilitando nosso aluno para uma leitura autônoma, estaríamos, proporcionando a êle uma oportunidade de um contato efetivo com uma língua e cultura dele tão distantes.

A leitura portanto, passou a ser 0 alvo de minhas reflexões. O verbo "àå $\phi \div \mathbf{i}$ " (likró), ler em hebraico, significa: ler, chamar alguém, falar alto (gritar). Curiosamente, nas duas últimas ações pressupõe-se uma interação, ação conjunta e não solitária e levando em conta a antiguidade da língua hebraica, mesmo o primeiro significado é uma ação conjunta, pois houve época em que apenas poucos eram os detentores do saber, e a leitura era realizada em voz alta para um público.

Esta palavra hebraica veio de encontro ao pensamento de Goodman, lingüísta que vê o leitor como um processador ativo da informação, o sujeito do processo do ato de ler. Para este autor, a leitura é um processo complexo no qual o leitor reconstrói, numa certa medida a mensagem codificada pelo escritor na sua linguagem gráfica. Segundo Goodman, para se compreender melhor este processo, é neces-

(*) Professora da Universidade de São Paulo. 
sário entender: a natureza do input gráfico; o funcionamento da língua; o uso da linguagem pelo leitor; em que medida o significado depende da aprendizagem anterior e da experiência do leitor na reconstrução do significado; e finalmente, o sistema perceptual envolvido na leitura.

Tanto ao falar como ao escrever, o significado cria na mente do falante/ escritor uma estrutura profunda de base e ativa aquele conjunto de regras que transformam a estrutura e geram as formas de superficie, a fala e/ou a escrita. O significado ativa uma cadeia automática de eventos, os quais resultam no código da língua, falada e/ou escrita e deve ser reconstruído pelo ouvinte e/ou leitor, com base nas suas experiências prévias com a língua. Para Goodman, a habilidade em recriar o significado depende, da capacidade que se tem em associar as experiências e os conceitos formados através delas com a linguagem. Portanto, reconstruir um significado não seria como refletir uma imagem num espelho, pois, nem todos os fatos são tomados como relevantes para a compreensão, isto é, a reconstrução é seletiva. Assim sendo, o conhecimento que o indivíduo tem da estrutura da língua o capacita a selecionar as deixas linguísticas produtivas, como também o capacita a predizer e antecipar o significado.

Dentro desta concepção, o leitor durante o processo de leitura, utiliza as informações grafofônica, sintática e semântica, o qual sendo conhecedor da linguagem oral traz consigo. No entanto, um material gráfico, escrito de forma fragmentada com letras e palavras isoladas, dificultará no ato da leitura, o uso do conhecimento que o leitor possui da língua. Formas fragmentadas não possuem componentes em seu sentido pleno, portanto não levaria a reconstrução do significado e sim a decodificação com a perda da compreensão.

Goodman (1970) in Braggio afirma ainda, ser a compreensão o único objetivo da leitura, sendo tudo o mais ou uma habilidade para se alcançar a compreensão, ou uma subcategoria da compreensão, por exemplo: a leitura crítica, ou um uso que se faz da mesma, como por exemplo, uma apreciação da literatura. Para o autor, a compreensão depende do processamento dos 3 tipos de informação (grafofônica, sintática e semântica) requeridos para a leitura e das estratégias utilizadas: movimentação e fixação ocular; selecionamento; predição; formação de imagens perceptuais; associação das imagens perceptuais à fonologia, sintaxe e semântica; escolha das deixas mais produtivas; testagem da escolha com base no significado e na gramática, ou ainda recorre-se à testagem grafofônica em busca de mais informação; e correção de anomalias ou inconsistências, decodificação, integração da informação gráfica com o significado.

Goodman (1984) in Braggio, acredita que a intenção do escritor com relação a uma determinada audiência, ao construir um texto, faz grande diferença para os processos de predição e compreensão do leitor, assim como a intenção do leitor, ao ler um texto, desempenha um papel crucial na construção do significado do texto. Portanto, o significado explicita-se durante o ato de ler, o que implica em que "o que um leitor compreende de um dado texto, variará em relação ao que outros leitores compreendem", uma vez que o que cada um traz para o ato de ler 
também varia. Portanto, as características de cada um e do próprio texto, influenciarão o significado resultante de uma leitura.

A psicologia cognitiva, partindo da premissa que a aquisição do conhecimento é um processo dinâmico, dialético, uma internalização desenvolvimental, que tem como ponto de partida as interações sociais que têm como base o significado, tem fornecido significativos subsídios para a compreensão do processo da leitura. Um exemplo disto, é a "teoria de esquemas" proposta por Rumelhart, 1981 in Braggio, que é basicamente uma teoria sobre o conhecimento.

A aquisição do pensamento é vista como um processo dinâmico que é "desenvolvido, estendido e modificado através da constante interação dos indivíduos e seu contexto social" (Wertsch, 1983 in Braggio). Visto que todos os seres humanos interagem num determinado contexto sócio-cultural, todos possuem esquemas baseados em suas experiências, desta forma os esquemas não podem ser vistos como dados a priori, nem estáticos, mas como dinâmicos, pois, além de emergirem através das interações do indivíduo com o ambiente, estão constantemente crescendo e se modificando para acomodar novas experiências.

Ler não é uma resposta passiva ao input gráfico. Dentro da "teoria de esquemas" o objetivo é saber como o conhecimento do leitor interage e molda a informação sobre a escrita e como aquele conhecimento deve ser organizado para corroborar a interação (Adam e Collins, 1985 in Coracini).

A leitura portanto é um ato construtivo, pois, o leitor ao interagir com o texto constrói um significado. A compreensão da língua escrita é interacional, o leitor elabora sobre as idéias selecionadas de um texto para construir um significado (Spiro,1980 in Braggio). A interação com o texto se dá a partir do conhecimento prévio que o leitor traz consigo para o ato de ler, assim sendo, este conhecimento anterior de mundo e as experiências passadas, são a base para a compreensão da leitura.

Sabemos que o conhecimento anterior e os esquemas diferem de pessoa para pessoa, assim um dos problemas de compreensão de leitura em língua estrangeira, podem ser uma não confluência entre os esquemas de um leitor não nativo, $\mathrm{e}$ aqueles valores transmitidos através dos textos em língua estrangeira.

Durante o ato de ler, se dá também o processo de inferenciamento que é uma das estratégias cognitivas utilizadas pelo leitor, ligada a teoria dos esquemas. Segundo Trabasso in Braggio (1980), fazer inferência é encontrar relações semânticas e/ou lógicas entre as proposições ou eventos que não estão expressos na narrativa, ou preencher a informação que é necessária para fazer tais conexões entre eventos. O leitor infere o que não está explícito, a fim de estabelecer relações entre os diferentes segmentos causais e proposicionais (Rumelhart e Ortony, 1977 in Braggio).

Segundo Trabasso, o processo de inferenciamento, preenche as seguintes funções: 
1. resolver ambigüidade lexical (decidir sobre significado);

2. resolver referências anafóricas (remeter uma expressão referencial ao seu referente);

3. resolver sobre tópico ou tema;

4. estabelecer um esquema mais amplo de interpretação.

O autor ainda afirma que o leitor deve possuir um conhecimento anterior sobre o conteúdo tratado pelo texto, a sua estrutura, as normas sócio-culturais nele expressas e as relações causais entre eventos.

Assim sendo, chegamos a duas premissas:

-o leitor chega ao texto com esquemas baseados em suas experiências culturais, os quais estão prontos para serem ativados, modificados e expandidos;

-o texto é o material por excelência a ser utilizado desde o princípio da alfabetização, já que fragmentos de língua dificultam o processo de inferenciamento.

Outro ítem importante que está intrinsecamente relacionado à "teoria dos esquemas" e ao papel do texto no processo de alfabetização, é a "memória", ou seja, a maneira como o significado é armazenado na memória. Este fato é de extrema importância para que se compreenda o processo de leitura.

Smith (1982) distingue 3 tipos de memória, a sensória, a de curto-termo e a de longo-termo. Para Clark e Clark, a memória de curto-termo tem uma capacidade limitada de armazenar informação, ao passo que a de longo-termo tende a preservar o significado e tem capacidade de armazenar um conjunto infinito de proposições e parece não ter limite de persistência. A informação permanece por mais ou menos um segundo na memória de curto-termo, podendo apagar-se em seguida se não for integrada na memória de longo-termo.

A entrada do texto na memória de longo-termo, depende da apreensão, da construção do significado. "Se, se compreende, se, se constrói o significado do que se lê ou ouve, a memória de longo-termo se reorganiza tão eficientemente e sem esforço, que nem sentimos quando aprendemos" (Smith, 1982).

Pesquisas nos revelam que a proposição é a unidade básica da memória de longo-termo. Isto posto, na leitura, letras, sílabas e frases fora do contexto serão dificilmente armazenadas na memória de longo-termo. Smith ainda se refere a "visão tunel", ou seja, o resultado da tentativa de processar muita informação visual, o que provocará uma sobre-carga na memória de curto-termo, não permitindo que a informação se organize de modo que possibilite a compreensão. "Se corrigirmos uma criança por pronunciar mal uma palavra, enquanto ela está lendo, interrompemos o fluxo de construção do significado, e o que já foi para a memória é apagado" (Smith). 
Visto que o "texto" é a unidade básica da memória de longo-termo, lingüístas e psicólogos cognitivos, preocupados com uma visão holística da linguagem e com o processo de aquisição e retenção da linguagem escrita, o tem focado em seus estudos.

Halliday e Hasan (1973) in Fávero definem o "texto" como uma "realização verbal entendida como uma organização de sentido, que tem o valor de uma mensagem completa e válida num contexto dado"; "o texto é unidade de língua em uso, unidade semântica (...) não de forma e sim de significado"

Beaugrand e Dressler (1983) in Fávero definem o "texto" como uma "ocorrência comunicativa" que possui 7 "padrões de textualidade" ou "princípios constitutivos" que contribuem para um texto unificado, a saber:

1. COESÃO a qual se manifesta pelo que é visto ou ouvido, apoiando-se na dependência gramatical (conjunções, substituições, elipse)

2. COERENCIA que constitui as relações subjacentes dos conceitos e suas relações. Estas relações nem sempre são explícitas e o leitor recorre ao seu conhecimento prévio através da inferência.

3. INTENCIONALIDADE que consiste na contribuição do escritor para distribuir conhecimento ou atingir um objetivo.

4. ACEITABILIDADE a qual leva em consideração a postura do leitor frente ao texto e a expectativa do leitor quanto ao mesmo.

5. INFORMATIVIDADE que leva a aceitação ou não do texto pelo leitor, segundo o grau de interesse da informação que o mesmo traz para o leitor.

6. SITUACIONALIDADE a qual representa a adequação social do texto.

7. INTERTEXTUALIDADE fator que torna o conhecimento de um texto dependente do conhecimento de outros textos.

Além destes princípios há ainda o que se convencionou a chamar de "gramática das histórias" que é a maneira como as histórias se estruturam internamente, o fio condutor que as organiza dentro de uma determinada seqüência. Baseados na estrutura subjacente hierárquica das histórias, proposta por Rumelhart (1975) in Braggio, Mandler e Johnson (1977) in Braggio postulam para as histórias uma série de sequências que podem ser distinguidas através de seis módulos principais: começo, situação, ação, reação, resultado e final. Segundo os autores, esta estrutura subjacente possibilita uma melhor retenção da história lida, pois possibilita o uso pleno dos processos de inferenciamento e de predição.

Esta estrutura subjacente, ou superestrutura como também é chamada, foi desenvolvida sobretudo por Van Dijk in Fávero e pode ser caracterizada como a forma global do texto, que define sua ordem e as relações entre seus fragmentos. Esta superestrutura pode ser descrita em termos de categorias e regras de formação. Teremos assim as seguintes categorias para textos narrativos: situação, complicação, ação ou avaliação, resolução, moral ou estado final; para textos 
argumentativos teremos: tese anterior-premissa, argumentos, contra-argumentos, síntese, conclusão-nova tese, etc.

As superestruturas são elementos de natureza cognitiva, organizadas culturalmente na memória em forma de diferentes tipos de textos, podemos dizer que as superestruturas são culturalmente dependentes, e se relacionam a tipologia de texto.

Influenciados pela concepção de leitura e escrita da lingüística contemporânea, as palavras $C O M U N I C A C ̧ \tilde{A} O$ e $F U N C ̧ \tilde{A} O$ passam a nortear o pensamento dos autores em relação ao ato de ler e escrever. Para Goodman é necessário enfocar a linguagem escrita do ponto de vista da comunicação, no seu aspecto funcional, o autor também salienta o papel importante do conhecimento prévio do leitor, do nível de confiança do leitor na compreensão e as características do texto lido.

Goodman in Braggio sustenta que o processamento dos ciclos e estratégias requeridas no ato de ler é simultâneo, todos interagindo ao mesmo tempo. $\mathrm{O}$ autor afirma também que sua concepção de leitura não se focaliza somente no leitor inside-out view, de dentro para fora, e nem somente no texto outside-out view, de fora para dentro. Para o autor o ato de ler é interacional, o leitor interage com o texto.

Sob este ponto de vista:

a) O texto é visto como a unidade básica da língua tomada holisticamente;

b) O significado está no texto e na cabeça do leitor;

c) A leitura é um processo destes dois sistemas de significado interagindo;

d) Os "erros" são vistos como tentativas de chegar ao significado, à leitura/ escrita convencional.

Na visão interacionalista de leitura, postula-se a interação entre o leitor e o texto, sujeito e objeto de conhecimento. Contudo, terminado o ato da leitura, ambos se separam percorrendo caminhos diferentes.

$\mathrm{Na}$ visão sociopsicolinguística, leitor e texto não apenas se tocam, mas, no processo se transformam. Segundo Rosenblat, 1978 in Braggio, o ato de ler deve ser visto como "um evento envolvendo um indivíduo e um texto em particular, acontecendo num momento específico, sob circunstâncias específicas, num contexto social e cultural específico, como parte envolvente do indivíduo e do grupo" Neste paradigma, leitor e texto são vistos como "partes ou aspectos de um evento total" onde "transação designa um processo em andamento" Esta transação é algo que ocorre entre leitor e texto, ou seja, o significado. Goodman e Rosenblat chamam seu modelo de leitura de transacional, já Harste et al. usa o termo sociopsicolinguístico.

Segundo Goodman, a leitura, assim como a audição são processos receptivos, onde o significado é construido através de transações diretas do leitor com o texto e indiretas com o escritor. Dentro desta perspectiva, a leitura leva em conta as intenções dos participantes neste ato, a disposição do leitor/escritor num dado momento sócio-histórico-cultural. 
O processo de leitura é considerado sociopsicolinguisticamente unitário, porém flexível, já que ele varia conforme: o objetivo do escritor/leitor, a audiência, a proficiência, a língua, a visão de mundo e o momento sócio-histórico-cultural do sujeito e do grupo. Portanto, o processo de leitura apesar de unitário, implica numa diversidade dentro da unidade.

Para Goodman, a informação disponivel é usada pelo leitor de maneira integrada através de estratégias cognitivas de:

1. iniciação ou reconhecimento da tarefa - intenção

2. mapeamento e seleção do input gráfico - esta estratégia depende do que o leitor sabe com relação à língua, ao ato de ler e ao texto em questão.

3. inferência- que são as informações implícitas ou explícitas, com base no que é conhecido.

4. predições - que é a capacidade de predizer o que vem a seguir. Se baseia em informações explícitas e inferidas de tal modo que o leitor não está seguro do que estava explícito e do que foi inferido.

5. confirmação e/ou não comfirmação- checagem de consistência da nova informação através de inferências, prediçôes e conhecimentos passados. Seria o automonitoramento.

6. correção - é a reconstrução do texto, o recobrar do significado se este não foi confirmado, através: da reavaliação inferindo, predizendo ou dando uma interpretação alternativa; ou ainda repassando o texto a procura de mais informações.

7. determinação - que é a intenção de findar o ato de ler.

Para o autor, o processo de ler envolve também ciclos:

- ótico - o texto é processado oticamente;

- perceptual - o texto é transformado perceptualmente

- sintático e semântico - depois do texto transformado perceptualmente, os sistemas da língua passam a ser usados.

Cada ciclo mistura-se ao outro e é tentativo e parcial já que as inferências e predições possibilitam ir em direção ao significado sem que se completar amplamente os ciclos.

Como já dito acima, a intenção e o objetivo desempenham papel importante no ato de ler. Ao avaliarmos a leitura com foco na compreensão, tomada como um produto final do ato de ler, a intenção afetará fortemente esta compreensão, ou seja, um professor ao avaliar a compreensão de seu aluno pode não obter deste a resposta esperada, por que as intenções do aluno e do professor podem não coincidir. Porém, se o objeto da avaliação for "o processo de compreender", isto é, "o processo de construção do significado, durante o processo de leitura", não haverá a interferência da "intenção". pois, o significado pode ser mudado durante o ato da leitura, através do uso das estratégias cognitivas acima apontadas. 
As características pessoais do escritor são outro fator relevante para a compreensão da leitura, isto inclui a noção de audiência e as características do texto, assim, um escritor ao escrever seu texto tem em mente uma audiência segundo a qual será mais ou menos explícito, fato que influenciará também nos processos de predição e inferenciamento do leitor. Portanto, ao escrevermos uma carta a um amigo e supondo um compartilhar de experiências, seremos menos explícitos ao passo que ao redigirmos um artigo, para relatar uma experiência não compartilhada pela audiência, deveremos ser o mais explícitos possível para nos fazermos compreendidos. Logo, "à medida que a distância entre escritor e leitor aumenta, $o$ escritor necessitará contrabalançar seu sentido de audiência com o sentido de quanta informação e detalhe devem ser dados" (Goodman, 1984).

Entre escritor e leitor, há um pacto oculto, onde o escritor cria um significado potencial que deve ser construido pelo leitor no ato de compreender. Portanto o escritor deve criar dentro de restrições de propósito, conteúdo, língua, lógica, estrutura e forma, dentro de contextos situacionais e sociais. Goodman, considerando o texto como unidade básica da língua, afirma que este deverá sempre ser organizado de forma que o significado seja representado de forma coerente e coesiva, para que se efetue "o pacto oculto"

A macro-estrutura de qualquer texto deriva pelo menos parcialmente das relações entre o conjunto de informação a ser apresentado, suas estruturas intrínsecas, e restrições especiais. Esta afirmação de Goodman se refere às estruturas internas de cada texto, em relação à sua função e aos seus leitores. Por exemplo, uma lista telefônica e uma história infantil, terão um formato diferente, como também terão estruturas e restrições diferenciadas, isto facilitará a compreensão do usuário.

$\mathrm{O}$ ato de ler é um processo de reconstrução de um significado, onde a língua escrita deve ser abordada pelo significado, pois normalmente este precede a identificação de letras ou palavras. "Processos lingüísticos de nível mais alto, a semântica e o significado, facilitam o processamento dos de nível mais baixo, as letras e as palavras, assim sendo, o domínio dos primeiros facilita o domínio dos últimos" (Rumelhart, 1985).

Reforçando esta idéia, diríamos que o ato de ler é somente parcialmente visual e o leitor traz para este ato o seu conhecimento anterior da língua, como também sua experiência de vida. Segundo Smith, o conjunto de processamento da informação visual pelo cérebro é limitado, por isso deve-se contar mais com o que já se conhece. Goodman vai além, para ele, o significado está na mente do leitor e do escritor. Assim sendo, o texto teria o potencial para evocar o significado, mas não o significado em si.

A leitura seria portanto, um processo transacional que culmina num novo evento; o significado é o resultado do encontro entre leitor e texto, numa situação específica, variável entre diferentes leitores e também entre momentos diferentes de um mesmo leitor; a leitura permite uma transformação do leitor, sendo que isto anula a concepção de erro. 
p. $103-111,1992 / 1993$.

Conforme a concepção de Paulo Freire, o homem é um ser real, relacionado com seu contexto, ativo, capaz de mudar a si e a sociedade que o circunda através da linguagem e de sua práxis. Quanto mais o Homem reflete sobre a realidade, sobre a situação concreta, mais emerge, plenamente consciente, comprometido, pronto para intervir na realidade para mudá-la. Partindo deste pressuposto, não basta construir um significado para o texto, é necessário que o leitor também entre em confronto com o texto, com as idéias do autor, com as intenções e possa avaliar em que medida os dados disponíveis através do material escrito entram em contradição com a sua realidade. Também é preciso através da linguagem escrita, construir a consciência crítica do indivíduo, possibilitando-lhe uma reflexão sobre sua realidade, uma leitura de mundo, uma leitura de sua situação concreta.

Segundo Coracini, leitor competente é aquele que é capaz de adicionar conhecimentos relevantes no momento adequado, relacionar, inferir, perceber as intenções do autor, através da linguagem por êle empregada e através dos dados do próprio texto. Concluindo, podemos dizer que se a leitura em língua materna exige do leitor uma rede complexa de procedimentos sem os quais não será possível ler significativamente um texto, a leitura em língua estrangeira exigirá do leitor ainda mais criatividade em seus procedimentos de leitura.

\section{BIBLIOGRAFIA}

BRAGGIO, Silvia L. B. -"Leitura e Alfabetização"- da concepção mecanicista à sociopsicolinguístca"- Artes Médicas, 1992, Porto Alegre.

CORACINI, M. J. R. F - "A progressão do curso de leitura (LE)" - comunicação apresentada na ENPULI - Congresso Nacional de Professores de Inglês-PUC/SP-07/07/83.

- "Leitura: decodificação, processo discursivo...?" Estudos lingüísticos XVII anais de seminários do GEL-USP/SP - 1989.

FÁVERO, Leonor L. -"Coesão e Coerência textuais" Ática, 1991, São Paulo. e KOCH, INGEDORE G. V.- "Lingüística Textual: introdução"- Cortez, 1988 (2a edição).

FOBË, N. L. - "A Leitura: uma forma de desconstruir e construir novas visões de mundo", in Letras, vol.9, ns 1 e 2, 1990, PUCCAMP.

FREIRE, Paulo - "A importância do ato de ler - em três artigos que se completam"- CORTEZ, 1982.

KLEIMAN, Ângela - "Texto e Leitor - aspectos cognitivos da leitura"- PONTES, 1989.

SMITH. F. "Compreendendo a Leitura - uma análise psicolingüística da leitura e do aprender a ler", tradução de Daise Batista, Artes Médicas, Porto Alegre, 1989.

ABSTRACT: This paper intend to be a reflection about reading as an interative process between writer/text/reader, wich will result in the reader's construction of the meaning of the text. 